TI 2014-009/VII

Tinbergen Institute Discussion Paper

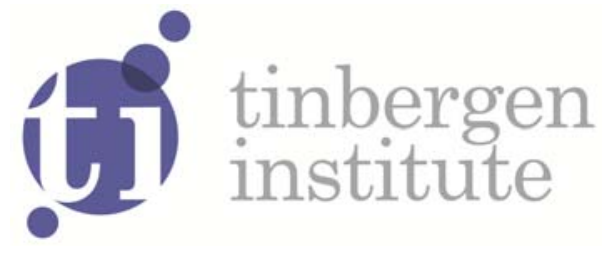

\title{
Social Relations, Incentives, and Gender in the Workplace
}

Okemena Onemu 
Tinbergen Institute is the graduate school and research institute in economics of Erasmus University Rotterdam, the University of Amsterdam and VU University Amsterdam.

More TI discussion papers can be downloaded at http://www.tinbergen.nl

Tinbergen Institute has two locations:

Tinbergen Institute Amsterdam

Gustav Mahlerplein 117

1082 MS Amsterdam

The Netherlands

Tel.: +31(0)205251600

Tinbergen Institute Rotterdam

Burg. Oudlaan 50

3062 PA Rotterdam

The Netherlands

Tel.: +31(0)10 4088900

Fax: $+31(0) 104089031$

Duisenberg school of finance is a collaboration of the Dutch financial sector and universities, with the ambition to support innovative research and offer top quality academic education in core areas of finance.

DSF research papers can be downloaded at: http://www.dsf.nl/

Duisenberg school of finance

Gustav Mahlerplein 117

1082 MS Amsterdam

The Netherlands

Tel.: +31(0)20 5258579 


\title{
Social Relations, Incentives, and Gender in the Workplace*
}

\author{
Okemena Onemu ${ }^{\dagger}$
}

January 29, 2014

\begin{abstract}
Gender differences in preferences regarding social relationships and competitive environments are well documented in psychology and economics. Research also shows that social relationships and competition among co-workers are affected by the incentive schemes workers are exposed to. We combine these two stylized facts and hypothesize that men and women differ in how they rate their co-worker relationships when they work under individual incentives, group incentives, or a combination of the two. This hypothesis is explored using survey data on 14,743 highly educated employees from 78 different organizations in the Netherlands. We find correlational evidence that, in the absence of individual incentives, group incentives improve co-worker relationships for women, but deteriorate co-worker relationships for men.
\end{abstract}

Keywords: Incentives, gender differences, interpersonal relations, social interaction.

JEL: J3; M52

*For constant support and advice, I would like to thank Robert Dur. I am also grateful to Kea Tijdens (AIAS) for consolodating part of the data used in this study and for making these data available. I also thank SatisAction for making data available.

${ }^{\dagger}$ Department of Economics, Erasmus University Rotterdam, and Tinbergen Institute. Email: onemu@ese.eur.nl 


\section{Introduction}

In economics, we typically evaluate incentive devices through the effects they have on worker productivity. However, literature indicates that the consequences of implementing incentives are not limited to productivity alone. In this paper we investigate the relation between the quality of co-worker social relations and the presence of individual incentives, team incentives, or both, using observational data from a large scale survey among Dutch employees. Empirical research in organizational psychology and management suggests that organizations should care about the effect incentive devices may have on co-worker relations. The quality of co-worker relations has been shown to be an important determinant of job satisfaction (Hodson, 1997; Ducharme and Martin, 2000; Morgeson and Humphrey, 2006; Westover and Taylor, 2011), commitment to an organization (Riordan and Griffeth, 1995), and turnover (Price and Mueller, 1981; Morrison, 2004; Chiaburu and Harrison, 2008; Skaalvik and Skaalvik, 2011). In line with this, recent studies suggest that satisfaction regarding coworker relations allow firms to pay lower wages (Borzaga and Depedri, 2005; Hamilton et al. 2003).

Why might incentive schemes have an effect on co-worker relations? Dur and Sol (2010) take a game-theoretical approach to analyze such effects. They find that the use of team or relative incentives can stimulate social interaction between co-workers. The intuition is that social interaction may promote coworker altruism, which in turn helps to resolve the free-rider problem in case of team incentives and facilitates (tacit) collusion in case of relative incentives. Other theoretical studies have focused on helping behavior or cooperation in the workplace, finding that team incentives promote these behaviors, while individual incentives lead to a reduction of such behaviors (FitzRoy and Kraft, 1986; Drago and Turnbull, 1988; Itoh, 1991; Rob and Zemsky, 2002; and Corneo and Rob, 2003) . Empirical research also suggests that incentives can affect cooperative and competitive attitude towards co-workers. Mitchell and Silver (1990) examine goal setting in an experiment where students face individual goals or group goals. They assess feelings of cooperation and competition among participants and find them to be more competitive and less cooperative in the treatment where participants face individual goals. Other experiments, such as that of Barnes et al. (2004) and Quigley et al. (2007) find similar results. Participants facing individual incentives choose to cooperate less compared to the treatment in which they face group incentives. We hypothesize that such a change in focus on one's individual outcome rather than that of the group as a whole can affect the perception of social relations within the group. This is in line with what would be expected based on cooperation theory (Deutsch 1949a, 1949b, 1973) which states that goal interdependencies positively affect social relations within the group. This theory has found support in empirical studies which find that in comparison to individual goals, cooperative goals have a 
positive effect on actual assistance, communication, and support between group members (De Vries and Slavin 1978; Hamblin et al. 1971).

In addition to studying the relationship between incentives and social relations among co-workers, we examine whether individual and group incentives affect the perception of social relations differently for men and women. There are two types of observations from empirical and experimental research underpinning our expectation of this gender difference. First, gender differences in preferences for type of peer-relationships have been well established in psychology. Jarvinen and Nicholls (1996) look at the social goals that are involved in adolescent peer relationships through a questionnaire answered by first-year high school students. While male students score significantly higher in the importance they place on competitive social goals such as dominance and leadership, female students score significantly higher in social goals described as intimacy and nurturance. Generally, studies in psychology find differences between genders in the preferred level of intimacy in relationships, where women prefer more intimate relationships than men (Agrawal et al., 2002; Sy et al., 2003; Rose and Asher 2004; Vigil, 2007). The change in behavior caused by incentives can therefore affect the perception of social relations differently for men and women: These new behaviors can lean towards either a male or female preference of how colleagues interact. More concretely, we expect women to rate co-worker relationships higher when team incentives are introduced. This expectation is reversed for individual incentives, since such incentives can entail an element of competition. For men, we expect the opposite.

A second reason for gender differences in preferences relies on a difference in social norms men and women are subjected to. Research indicates that Western societies promote and reward autonomy and independence in men, while promoting pro-social behavior and interdependence in women (Bakan 1966; Maccoby 1990; Markus and Oyserman 1989). Pan and Houser (2011) provide an overview of gender differences in pro-social behavior including theories from psychology as well as empirical findings from experimental economics. Examining this literature, they find that women have a preference to conform to social norms that dictate pro-social behavior. Hibbard and Buhrmester (2010) study the social and emotional downside to competitiveness among 12th grade students and find that female students that score high on their measure of competitiveness have less succesfull interpersonal relationships with their peers. They believe this is due to competition being a male type trait that is at odds with existing social norms for females. In our context such gender differences may imply that women are less successful in maintaining good social relationships in environments that foster competitive behavior through individual incentives, but more successful in maintaining these relationships when incentives call for pro-social behavior. Again, we expect the reverse for men.

Summarizing, we hypothesize that women's perceived co-worker relationships are affected positively by group incentives and negatively by individual incentives, while men's perceived co-worker relations are negatively affected by group incentives and positively affected by individual incentives. This gender difference in the effect of incentives on social relations has largely gone unex- 
plored. Heywood and Wei (2006) use representative US survey data to examine the effects of several incentive devices on overall job satisfaction. In their analysis, they separate these effects on overall job satisfaction for men and women, but do not do so for their measure of co-worker relationships. While they do not find any evidence that performance pay influences co-worker relationships for the full sample, it is unclear what they would find if they seperated these effects for men and women. Artz (2008) uses UK representative survey data and looks at gender differences in the relation between incentives and overall job satisfaction. Coworker friendliness is one of the facets of job satisfaction in the data. He finds no significant relation between individual performance pay and the way respondents rate co-worker friendliness for either gender. However, he does find that in other facets of job satisfaction men respond more favorably to individual incentive pay, and suggests that this may be due to men having a preference for a more competitive environment.

In our study, we use data from an employee-employer survey conducted in 78 large corporations in the Netherlands in 2005 and 2007. The employee survey contains a question on satisfaction regarding co-worker social relations in the workplace. The employer survey includes items on a number of possible determinants including reward structure, sector, and percentages of part-time employment in the organization. The data allow us to control for individual heterogeneity and observable company characteristics. Combining both years, the entire sample counts 14,743 respondents.

Our key findings are that the presence of a group incentive is negatively related to satisfaction with co-worker relations for men, while women rate their co-worker relations better when provided with a group incentive. The presence of individual incentives is not related to the way women rate their social relations on the workfloor, while it has a significantly positive relation with the way men rate these relationships. Lastly, we find indications that the effect of the presence of a group incentive on co-worker social relations is negated when combined with an individual incentive. These findings are correlational, but nevertheless striking in the sense that they show that incentives and co-worker relations are connected in an important way, and that gender plays an essential role in the way they are related.

The rest of our paper is organized as follows. In section 2 we describe the data. Section 3 describes the methodology. In Section 4 we present our findings and Section 5 concludes.

\section{Data}

The survey data we use were originally collected for a yearly ranking of organizations based on employee satisfaction, HRM-policies, and working conditions. The results are published in Intermediair, a Dutch weekly magazine with careerrelated articles for the highly educated. Data are gathered through pen and pencil surveys. The employee survey data were collected by the research bureau SatisAction in collaboration with Tilburg University. Additionally, we use the 
Table 1: Descriptive statistics

\begin{tabular}{lccc} 
& Total sample & Men & Women \\
\hline Percentage of women & 37.2 & & \\
Non-profit & 34.7 & 34.0 & 35.7 \\
Percentage of part-time employees & 22.8 & 20.6 & 26.6 \\
Management position & 23.1 & 27.8 & 15.2 \\
Age 16-25 & 7.6 & 6.5 & 9.5 \\
Age 26-35 & 34.3 & 30.3 & 41.1 \\
Age 36-45 & 31.2 & 30.8 & 31.9 \\
Age 46-55 & 21.2 & 25.3 & 14.3 \\
Age 56 and older & 5.6 & 7.1 & 3.0 \\
Lower vocational training & 0.9 & 0.9 & 1.0 \\
Intermediate vocational training & 24.5 & 21.4 & 29.9 \\
Higher vocational training & 43.8 & 46.0 & 40.0 \\
University & 22.9 & 22.9 & 23.0 \\
Post-university & 7.8 & 8.8 & 6.2 \\
Year 2005 & 26.2 & 25.5 & 27.5 \\
\hline
\end{tabular}

employer survey data collected for Intermediair by the Amsterdam Institute of Labor Studies (AIAS). These surveys are conducted among the HRM-managers of the organizations. We merge these two sets of survey data to learn how the perceived social relations in the employee survey are related to the information regarding the prevailing incentives provided by HRM managers.

Both for-profit and non-profit organizations from a range of different sectors are included in our dataset. We use the survey data from the years 2005 and 2007, because only in these years HRM-managers were asked whether the company provided individual and/or group incentives. We have dropped all observations that missed responses to questions that are relevant for our analysis. A small number of organizations were a part of the sample in both 2005 and 2007. For these organizations we only included the data from the year in which they contributed most survey respondents. This results in dropping 4,636 observations, giving us a total of 14,743 respondents from 78 different organizations. As a requirement for participation in the survey, organizations needed to have a minimum of 100 employees. Respondents were fairly spread out across organizations with only 3 organizations contributing more than 5 percent to the sample, and none contributing more than 10 percent. Organizations in the survey cover a total of 21 sectors. Most respondents come from financial institutions, insurance companies, ICT companies, government services, and government organizations. Combined, these five sectors account for almost 75 percent of the respondents included in the analysis. The descriptive statistics are summarized and split out by gender in Table 1 .

Of our respondents 37.2 percent is female. The average percentage of female employees within sectors is 36 with a standard deviation of 14.7. ICT companies and companies active in the steel industry have the lowest percentage of 
Table 2: Pleasant social relations with direct colleagues

\begin{tabular}{lccc} 
& Total \% & Men \% & Women \% \\
\hline Strongly Disagree & 0.5 & 0.5 & 0.4 \\
Disagree & 1.8 & 1.8 & 1.6 \\
Neutral & 9.0 & 10.0 & 7.4 \\
Agree & 52.9 & 54.1 & 50.9 \\
Strongly Agree & 35.9 & 33.6 & 39.7 \\
\hline
\end{tabular}

females in our sample. The percentage of female respondents in these sectors is 17.9 percent and 19.3, respectively. Employment agencies have the highest percentage of females in our sample. In this sector 78.6 percent of the respondents are female. Men and women differ in their levels of education, with men being slightly higher educated than women. Out of the men in the sample, 77.7 percent has at least had higher vocational training, while this percentage is 69.2 percent for women. Significantly more men than women hold a management position within the organization and significantly more women indicate that they work part-time.

In our analysis, we relate the reported quality of co-worker relations to the presence of an individual or group incentive and investigate whether gender plays a role in the relationship between the two. We measure the quality of co-worker relationship satisfaction by the response that is given to the statement: "The social relations with my direct colleagues are pleasant". Responses are recorded on a 5 point Likert scale where respondents could indicate the degree to which they agreed with this statement. Possible responses ranged from "I strongly disagree" to "I strongly agree". The statement mentions direct colleagues, making respondents focus on interactions in their own environment rather than impressions they may have from the organization as a whole. Aggregated responses to this question can be found in Table 2. On average, women are somewhat more positive about co-worker relationships, though the difference is not statistically significant.

Out of the respondents in our sample, 76.4 percent received an individual incentive, while 47.2 percent received a group incentive. Within our sample it is quite common that respondents receive both an individual and group incentive. This is the case for 41.8 percent of the respondents. Table 3 gives an overview of the incentive schemes respondents were exposed to. The respondents that only receive a group incentive are from 4 different companies, active in 3 different sectors. These are electricity (14.9\%), ICT (45.8\%) and employment agencies $(39.3 \%)$.

\section{$3 \quad$ Methodology}

We use an ordered probit estimation model accounting for the fact that our dependent variable, the response a worker gives on a 5-point Likert scale, is 
Table 3: Incentives

\begin{tabular}{llll} 
& Total $\%$ & Men $\%$ & Women $\%$ \\
\hline Individual incentive only & 34.5 & 35.2 & 33.3 \\
Group incentive only & 5.4 & 5.5 & 5.2 \\
Individual and group incentive & 41.8 & 41.2 & 43.0 \\
No incentive scheme & 18.3 & 18.1 & 18.5 \\
\hline
\end{tabular}

ordinal. We control for age, level of education, whether respondents hold a managerial position, work part-time, whether respondents are working for a non-profit organisation, and for the year in which observations were gathered. We classified age into 5 age groups: 16 to 25,26 to 35,36 to 45,46 to 55 and 56 and older. We added sector dummies as control variables in the regression to control for systematic differences between sectors with regard to social relations among workers. Variation between sectors in our dependent variable could arise due to, for instance, market circumstances in the sector, differences in production technology, or sorting of workers with particular characteristics into a sector. We correct for potential clustering at the company level using $\mathrm{Hu}-$ ber/White corrected standard errors addressing the possibility of a downward bias in standard errors due to an underlying similarity of respondents within companies. The relation of the individual and group incentive schemes with the perception of social relations by the worker may not simply be additive. Instead, it might be the case that the effect of one type of incentive scheme depends on the presence of the other. For this reason we include dummies for respondents facing only individual incentives, only group incentives, and both individual and group incentives. Our basic model is as follows:

$$
Y_{i}^{*}=\beta^{\prime} X_{i}+\varepsilon_{i}, \text { where }\left(\begin{array}{rl}
1 & \text { if } Y_{i}^{*}<\tau_{1} \\
2 & \text { if } \tau_{1} \leq Y_{i}^{*}<\tau_{2} \\
3 & \text { if } \tau_{2} \leq Y_{i}^{*}<\tau_{3} \\
4 & \text { if } \tau_{3} \leq Y_{i}^{*}<\tau_{4} \\
5 & \text { if } \tau_{4}<Y_{i}^{*}
\end{array}\right)
$$

The outcome $Y$ can take on any of the integers 1 through 5, which represent the five possible responses to the statement: "The social relations with my direct colleagues are pleasant". These responses range from "I strongly disagree" (1) to "I strongly agree" (5). This outcome is determined by the underlying propensity denoted by $Y^{*}$. The threshold parameters delimiting each possible response or category are denoted by $\tau_{1}$ to $\tau_{4}$. The variable $X_{i}$ is a vector containing explanatory variables specific to each respondent. This includes the type of incentive scheme a respondent faces. The $\beta^{\prime}$ is a vector of coefficients, and $\varepsilon_{i}$ is the error term reflecting the influence of unobserved variables on the underlying propensity $Y_{i}^{*}$. This error term is assumed to be normally distributed. The expression $\beta^{\prime} X_{i}$ can be described as

$$
\beta^{\prime} X_{i}=\beta_{1} X_{1}+\beta_{2} X_{2}+\beta_{3} X_{3} \ldots \ldots+\beta_{N} X_{N} .
$$


The covariates are indicated by the variables $X_{1}$ to $X_{N}$. Three of these are dummy variables indicating whether a respondent faces only individual incentives, only group incentives, or both. To study the gender differences we perform the estimation seperately for men and women in our sample.

Estimated coefficients of our model need to be interpreted with some care. The sign of the coefficient only tells us how our independent variable relates to the probabilities of respondents choosing the end categories "I strongly disagree" (1) and "I strongly agree" (5) (Greene, 2002). After some straightforward calculations, we can get a clearer view of the way in which our independent variables relate to the predicted probabilities for each category. For example, the probability that a respondent with a specific set of values for our independent variables chooses category 1 , can be calculated as

$$
\begin{aligned}
\operatorname{Pr}(Y & =1)=\operatorname{Pr}\left(Y^{*}<\tau_{1}\right) \\
& =\operatorname{Pr}\left(\varepsilon_{i}<\tau_{1}-\left(\beta_{1} X_{1}+\beta_{2} X_{2}+\beta_{3} X_{3} \ldots \ldots+\beta_{N} X_{N}\right)\right) \\
& =\Phi\left(\tau_{1}-\beta^{\prime} X_{i}\right)
\end{aligned}
$$

where $\Phi(\cdot)$ describes the cumulative distribution function of the normal distribution. We calculate the probabilities of the categories 2 through 5 in a similar way. For the categories that are in-between the end categories, the calculation is

$$
\operatorname{Pr}(Y=C)=\operatorname{Pr}\left(\tau_{C-1} \leq Y_{i}^{*}<\tau_{C}\right)=\Phi\left(\tau_{C}-\beta^{\prime} X_{i}\right)-\Phi\left(\tau_{C-1}-\beta^{\prime} X_{i}\right),
$$

where $C$ indicates the response category. The probability of choosing the end response category, 5 , is expressed as follows

$$
\operatorname{Pr}(Y=5)=\operatorname{Pr}\left(\tau_{4}<Y_{i}^{*}\right)=1-\Phi\left(\tau_{4}-\beta^{\prime} X_{i}\right) .
$$

The marginal effect of our continuous independent variables, or the way in which our independent variables affect the above probabilities, can be calculated by taking the partial derivative with respect to these variables from the above equations (Greene, 2002). It is possible to find the marginal effects for our binary independent variables by calculating the difference in the above probabilities when these variables take on a value of either zero or one. While continuous variables would be kept at the mean, effects may remain unclear when keeping other binary variables at either a value of zero or one for this calculation. By doing this we would effectively evaluate differences in probabilities for only subsets of our sample. For this reason we follow Greene's suggestion (Greene 2002) and take the derivative with respect to our binary variables as if they were continuous for an accurate approximation.

\section{Empirical results}

Table 4 contains the ordered probit estimates. We run the estimation for both the whole sample and for men and women seperately. 
Table 4: Ordered Probit estimation results; dependent variable "The social relations with my direct colleagues are pleasant"

\begin{tabular}{|c|c|c|c|c|c|c|}
\hline & \multicolumn{2}{|c|}{ Total } & \multicolumn{2}{|c|}{ Men } & \multicolumn{2}{|c|}{ Women } \\
\hline & Coeff. & Prob. & Coeff. & Prob. & Coeff. & Prob. \\
\hline Non-profit & $\begin{array}{l}-0.113 \\
(0.122)\end{array}$ & 0.353 & $\begin{array}{c}-0.054 \\
(0.137)\end{array}$ & 0.693 & $\begin{array}{l}-0.394 \\
(0.295)\end{array}$ & 0.183 \\
\hline Perc. Women & $\begin{array}{l}0.203 \\
(0.135)\end{array}$ & 0.133 & $\begin{array}{l}0.235 \\
(0.180)\end{array}$ & 0.192 & $\begin{array}{l}0.117 \\
(0.212)\end{array}$ & 0.580 \\
\hline Part-time & $\begin{array}{l}0.178 \\
(0.119)\end{array}$ & 0.135 & $\begin{array}{l}0.376 \\
(0.162)\end{array}$ & $0.020 * *$ & $\begin{array}{l}-0.034 \\
(0.175)\end{array}$ & 0.845 \\
\hline Male & $\begin{array}{l}-0.140 \\
(0.021)\end{array}$ & $0.000 * * *$ & & & & \\
\hline Manager & $\begin{array}{l}0.143 \\
(0.024)\end{array}$ & $0.000 * * *$ & $\begin{array}{l}0.170 \\
(0.028)\end{array}$ & $0.000 * * *$ & $\begin{array}{l}0.073 \\
(0.046)\end{array}$ & 0.112 \\
\hline Age 26-35 & $\begin{array}{l}-0.056 \\
(0.038)\end{array}$ & 0.139 & $\begin{array}{l}-0.109 \\
(0.052)\end{array}$ & $0.034^{* *}$ & $\begin{array}{l}0.002 \\
(0.056)\end{array}$ & 0.969 \\
\hline Age $36-45$ & $\begin{array}{l}-0.189 \\
(0.039)\end{array}$ & $0.000 * * *$ & $\begin{array}{l}-0.247 \\
(0.052)\end{array}$ & $0.000 * * *$ & $\begin{array}{l}-0.130 \\
(0.059)\end{array}$ & $0.028 * *$ \\
\hline Age $46-55$ & $\begin{array}{l}-0.198 \\
(0.041)\end{array}$ & $0.000 * * *$ & $\begin{array}{l}-0.264 \\
(0.053)\end{array}$ & $0.000 * * *$ & $\begin{array}{l}-0.117 \\
(0.067)\end{array}$ & $0.080 *$ \\
\hline Age $56+$ & $\begin{array}{l}-0.159 \\
(0.054)\end{array}$ & $0.003 * * *$ & $\begin{array}{l}-0.203 \\
(0.065)\end{array}$ & $0.002 * * *$ & $\begin{array}{l}-0.146 \\
(0.114)\end{array}$ & 0.203 \\
\hline Interm. vocational training & $\begin{array}{l}0.075 \\
(0.084)\end{array}$ & 0.373 & $\begin{array}{l}0.071 \\
(0.104)\end{array}$ & 0.498 & $\begin{array}{l}0.085 \\
(0.143)\end{array}$ & 0.553 \\
\hline Higher vocational training & $\begin{array}{l}0.129 \\
(0.084)\end{array}$ & 0.121 & $\begin{array}{l}0.172 \\
(0.103)\end{array}$ & 0.096 & $\begin{array}{l}0.078 \\
(0.142)\end{array}$ & 0.586 \\
\hline University educ. & $\begin{array}{l}0.204 \\
(0.085)\end{array}$ & $0.017 * *$ & $\begin{array}{l}0.244 \\
(0.105)\end{array}$ & $0.020 * *$ & $\begin{array}{l}0.152 \\
(0.145)\end{array}$ & 0.295 \\
\hline Post university educ. & $\begin{array}{l}0.183 \\
(0.090)\end{array}$ & $0.042^{* *}$ & $\begin{array}{l}0.278 \\
(0.110)\end{array}$ & $0.012 * *$ & $\begin{array}{l}0.014 \\
(0.156)\end{array}$ & 0.931 \\
\hline Year 2005 & $\begin{array}{l}0.108 \\
(0.024)\end{array}$ & $0.000 * * *$ & $\begin{array}{l}0.117 \\
(0.031)\end{array}$ & $0.000 * * *$ & $\begin{array}{l}0.090 \\
(0.038)\end{array}$ & $0.018 * *$ \\
\hline Only Indiv incentive & $\begin{array}{l}0.102 \\
(0.033)\end{array}$ & $0.002 * * *$ & $\begin{array}{l}0.099 \\
(0.041)\end{array}$ & $0.015 * *$ & $\begin{array}{l}0.073 \\
(0.056)\end{array}$ & 0.192 \\
\hline Only Grp incentive & $\begin{array}{l}-0.017 \\
(0.059)\end{array}$ & 0.766 & $\begin{array}{l}-0.196 \\
(0.072)\end{array}$ & $0.006 * * *$ & $\begin{array}{l}0.375 \\
(0.102)\end{array}$ & $0.000 * * *$ \\
\hline Both Indiv and Grp incentive & $\begin{array}{l}0.117 \\
(0.036)\end{array}$ & $0.001 * * *$ & $\begin{array}{l}0.115 \\
(0.045)\end{array}$ & $0.011 * *$ & $\begin{array}{l}0.098 \\
(0.059)\end{array}$ & $0.094 *$ \\
\hline Log Likelihood & -14724.3 & & -9327.2 & & -5360.0 & \\
\hline LR statistic & 380.0797 & & 268.8958 & & 116.2151 & \\
\hline Prob. (LR stat) & 0.0 & & 0.0 & & 0.0 & \\
\hline Observations & 14,661 & & 9,208 & & 5,453 & \\
\hline
\end{tabular}

Notes: Standard errors are reported in brackets below the coefficients. Robust standard errors, corrected for clustering at the company level. ***,** and * indicate statistical significance at the $1 \%, 5 \%$ and $10 \%$ levels. 
Table 4 gives us an indication of which covariates are significantly related to our dependent variable. However, to get a sense of the magnitude of these effects, we calculate the marginal effect of the incentive schemes as described in Section 3. These are reported in Table 5. The numbers show the changes in the predicted probability of each of the choice categories on the 5 point Likert scale for a variation in the presence of individual incentives, group incentives, and both, allowing us to get a sense of the effect-size. Figure 1 depicts these marginal effects.

We obtain the following results. When looking at our total sample, only the provision of an individual incentive is related to perceived co-worker relations, while the group incentives are unrelated to our dependent variable. However, this result hides an important gender difference in the way these incentive schemes affect perceived co-worker relations. By running the estimation seperately for men and women, we observe a gender difference in the relationship between the incentive schemes and perceived co-worker relations. Specifically, being exposed to a group incentive has an opposite effect on the way men and women evaluate their social relations in the work place. The results are perhaps most clearly visible in Figure 1 . We see that men perceive their co-worker relations to be better when they face an individual incentive scheme. In the presence of this individual incentive, they are more likely to choose the response indicating that they strongly agree with the statement that social relations with direct colleagues are pleasant. This is matched by a reduction in the predicted probability of choosing response categories 1 through 4 . For women we observe a similar pattern, but weaker and not statistically significant. Most strikingly, a group incentive scheme affects our dependent variable in opposite ways for men and women. The middle of Figure 1 illustrates this effect. For men, the group incentive increases the probability of respondents choosing categories 1 through 4, while decreasing the probability of men choosing response category 5 by $7.1 \%$. Responses therefore shift towards the response categories that reflect a lower level of satisfaction regarding co-worker relations. For women, the estimated probabilities move in the opposite direction. While the probabilities of choosing response categories 1 through 4 decrease, the probability of choosing response category 5 increases by $14.4 \%$, indicating a higher level of satisfaction regarding co-worker relations.

When an individual bonus is included in conjunction with the group bonus, the effect the total scheme has on respondent's perceived co-worker relations is similar to the effect of having only an individual bonus scheme. One explanation for this result could be that whenever people face both individual and group bonus schemes, a conflict arises between individual interest on the one hand and group interest on the other. When workers place their individual interest above that of the group, and this is reflected in their actions, perceived coworker relations are similar to the situation where workers face only individual bonus incentives. In recent literature, several studies have indicated such a conflict when combining the use of individual and group incentives. Quigly et 
al. (2007) conduct a lab experiment focusing on the effects of incentive schemes on information sharing. They find that mixed incentives lead to lower levels of information sharing than group incentives. Additionally, they find no significant difference between information shared when participants face individual and when they face mixed incentives ${ }^{1}$. An alternative explanation that we can not rule out is that in organizations that offer both individual and group incentives, the individual incentives may be much stronger than the group incentives. Such a focus on individual incentives would lead workers to behave in a manner comparable to those facing only individual incentives, and result in the similarity of perceived co-worker relations that we find in the data.

\footnotetext{
${ }^{1}$ See Barnes et al. (2011) for a similar result.
} 


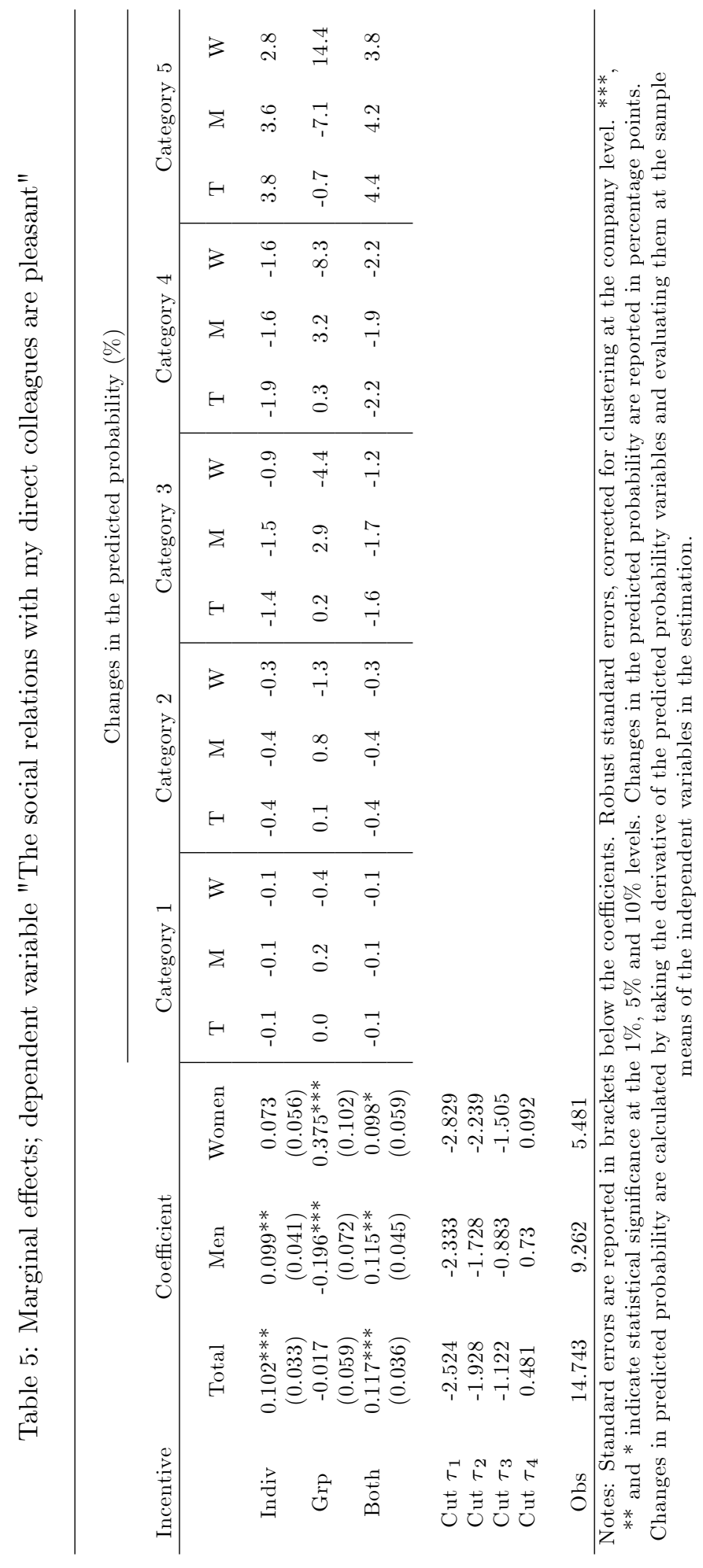




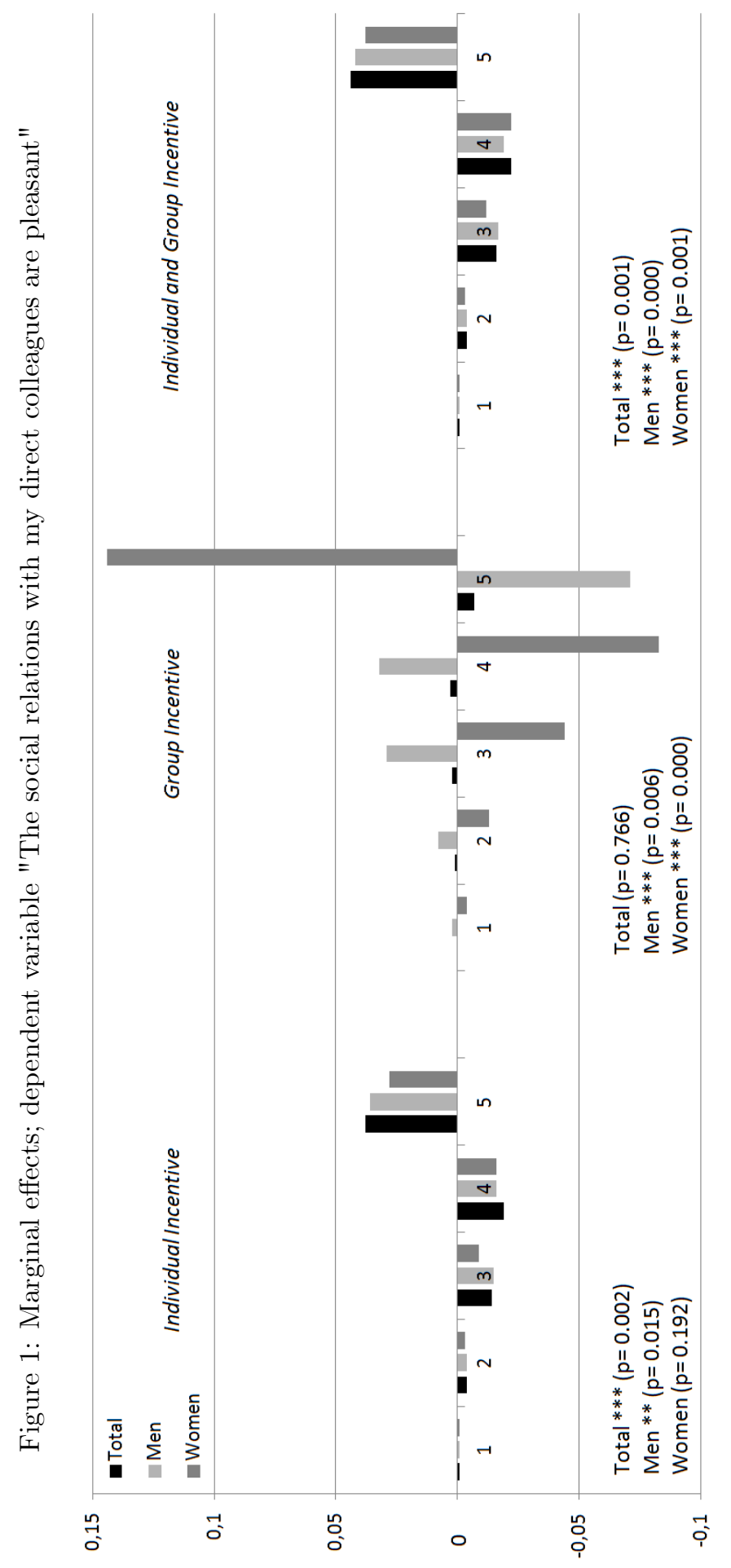




\section{Conclusion}

Theories as well as earlier evidence suggest that the use of incentives can have an important impact on the the way employees experience co-worker relationships. We have hypothesized that this relationship depends on both gender and the type of incentives employees are faced with. In our empirical analysis, we find a significant positive relation between individual incentives and co-worker relations for men. We see a similar pattern for women, but this relation is not significant. In line with our hypothesis, we find an opposite relation between incentives and co-worker relations for men and women when they are faced with only a group incentive. The estimated effect size is substantial. While the presence of group incentives relate to a 14.4 percent increase in the predicted probability of choosing to strongly agree with the statement "The social relations with my direct colleagues are pleasant" for women, for men the predicted probability of choosing this end category decreases by $7.1 \%$.

Estimates from our ordered probit model do not identify the direction of causation. There are two main reasons why endogeneity is a problem in our analysis. First, it is possible that there is a self-selection of respondents into specific payment schemes, or into jobs that are more likely to have a specific kind of payment scheme. Second, organizations choose the type of incentive that they wish to employ and may tailor these to pre-existing co-worker relationships. However, our estimates provide a sense of the magnitude of the association, and expose that gender plays a key role in the way incentives are related to the way workers experience their co-worker relations. Such a result has potential HR implications. It suggests that the use of incentive devices can have profound effects on co-worker relationships. Furthermore, when group incentives are used, these effects may differ widely by gender. Understanding the social effects these incentives can evoke can be important in several ways. When choosing incentives, being aware of such effects enables managers to use those incentive devices that match their employees and promote desirable social effects. When promoting gender diversity in the workplace, the use of the right kind of incentive can make a workplace environment simultaneously more attractive for women and less attractive for men, or vice versa.

This managerial implication is in line with those presented in a literature in economics that studies gender differences in competitive preferences in a lab setting. These lab experiments however do not stress or include social relations in their analysis. Instead, they find policy recommendations similar to the ones we present here, but based on a difference in preferences for competition between men and women. A preference for either a competitive or non-competitive environment ties into the use of incentives, as it is through the use of incentives that managers can either promote or suppress competitive behaviors on the workfloor. Niederle and Versterlund (2007) conduct such a lab experiment and find that for a given level of performance, there is a large gender gap when it comes to self-selection into tournaments, with men being far more likely to choose to compete than women. Dargnies (2012) studies gender differences in self-selection into tournaments in a lab experiment and also finds that men are 
more likely to participate in tournaments. Additionally, she finds that men are more likely to compete as individuals than they are as part of a team. Gneezy et al. (2009) confirm these findings when participants are part of a patriarchal society, but find that the gender difference in behavior is reversed when the experiment is conducted in a matrilineal society. Rather than focusing on selfselection into tournaments, Kuhn and Villeval (2014) allow participants in their experiment to choose either individual or team-based pay. They find that in comparison to men, women show greater attraction to team based pay.

Our study has the interesting feature that it suggests a related, but different kind of gender difference in preferences that is hard to pick up in a lab experiment setting and has not been addressed in previous literature in economics. While our data do not allow us to deal with some of the issues of endogeneity we encounter, we hope that our findings motivate future research on this topic. We are currently trying to set up a field experiment in which we are able to detect these social effects of incentive schemes and learn more about the gender differences that are related to them. A field experimental setup will also allow us to address the aformentioned issues of endogeneity.

\section{References}

[1] Agrawal, A., K. C. Jacobson, C. A. Prescott, and K. S. Kendler (2002), A twin study of sex differences in social support, Psychological Medicine, 32(7): 1155-1164.

[2] Artz, B. (2008), The role of firm size and performance pay in determining employee job satisfaction brief: firm size, performance pay, and job satisfaction, Labour, 22(2): 315-343.

[3] Bakan, D. (1966), The duality of human existence: An essay on psychology and religion. Boston, MA Beacon press

[4] Barnes, C., J. Hollenbeck, D. Jundt,.D. DeRue and S. Harmon (2011). Mixing Individual Incentives and Group Incentives: Best of Both Worlds or Social Dilemma? Journal of Management, 37(6): 1611-1635

[5] Beutell, N. and O. Brenner (1986), Sex differences in work values, Journal of Vocational Behavior, 28(1): 29-41.

[6] Block, J. (1983), Differential premises arising from differential socialization of the sexes: Some conjectures, Child Development, 54: 1335-1354.

[7] Borzaga, C., and S. Depedri (2005). Interpersonal relations and job satisfaction: Some empirical results in social and community care services, Economics and social interaction: Accounting for interpersonal relations, 132-153.

[8] Bowles, H. R., L. Babcock, and L. Lai (2007), Social incentives for gender differences in the propensity to initiate negotiations: Sometimes it does hurt 
to ask, Organizational Behavior and Human Decision Processes, 103(1): 84-103.

[9] Campion, M. A., G. A. Medsker, and C. A. Higgs (1993), Relations between work group characteristics and effectiveness: Implications for designing effective work groups, Personnel Psychology, 46(4): 823-850

[10] Corneo, G., and R. Rob (2003), Working in public and private firms, Journal of Public Economics, 87(7): 1335-1352.

[11] Croson, R. and U.Gneezy (2009), Gender differences in preferences, Journal of Economic Literature, 47(2): 448-474.

[12] Chiaburu, D. S., and D.A. Harrison (2008), Do peers make the place? Conceptual synthesis and meta-analysis of coworker effects on perceptions, attitudes, OCBs, and performance, Journal of Applied Psychology, 93(5): 1082.

[13] Dargnies, M. P (2012), Men too sometimes shy away from competition: The case of team competition, Management Science, 58(11): 1982-2000.

[14] De Vries, D. L. and R. E. Slavin (1978), Teams-Games-Tournaments (TGT): Review of Ten Classroom Experiments, Journal of Research and Development in Education,12(1): 28-38.

[15] Deutsch, M. (1949a), A theory of cooperation and competition, Human relations, 2:199-231

[16] Deutsch, M. (1949b), An experimental study of the effects of co-operation and competition upon group process, Human relations, 2:199-231

[17] Deutsch, M. (1973), The resolution of conflict: Constructive and destructive processes, New Haven, CT: Yale University Press

[18] Drago, R., and G. K. Turnbull (1988), Individual versus group piece rates under team technologies, Journal of the Japanese and International Economies, 2(1): 1-10.

[19] Ducharme, L. and J. Martin (2000), Unrewarding work, coworker support, and job satisfaction, Work and Occupations, 27(2): 223-243

[20] Dur, R. and J. Sol (2010), Social interaction, co-worker altruism, and incentives, Games and Economic Behavior, 69(2): 293-301.

[21] FitzRoy, F. R., and K. Kraft (1986), Profitability and profit-sharing, The Journal of Industrial Economics, 35: 113-130.

[22] Gneezy, U., M. Niederle, and A. Rustichini (2003), Performance in competitive environments: Gender differences, The Quarterly Journal of Economics, 118(3): 1049-107. 
[23] Gneezy, U., K. L. Leonard, and J.A. List (2009), Gender differences in competition: Evidence from a matrilineal and a patriarchal society, Econometrica, 77(5): 1637-1664.

[24] Greene, W.H. (2002) Econometric Analysis, 5th Edition, Prentice Hall.

[25] Kuhn, P. and M.C. Villeval (2014), Are women more attracted to cooperation than men? The Economic Journal, forthcoming.

[26] Hamblin, R. L., Hathaway, C., and J. S. Wodarski (1971), Group contingencies, peer tutoring, and accelerating academic achievement. In E. Ramp \& W. Hopkins (Eds.), A new direction for education: Behavior analysis. Lawrence, Kansas: The University of Kansas: 41-53.

[27] Hamilton, B. H., Nickerson, J. A., and H. Owan (2003). Team incentives and worker heterogeneity: An empirical analysis of the impact of teams on productivity and participation. Journal of Political Economy, 111(3): 465-497.

[28] Heywood, J. S., and X. Wei (2006), Performance pay and job satisfaction, Journal of Industrial Relations, 48(4): 523-540.

[29] Hibbard, D. R., and D. Buhrmester (2010), Competitiveness, gender, and adjustment among adolescents. Sex roles, 63(5-6): 412-424.

[30] Hodson, R. (1997), Group relations at work, Work and Occupations, 24(4): 426-452.

[31] Itoh, H. (1991). Incentives to help in multi-agent situations, Econometrica, 59: 611-636.

[32] Iverson, K. (2000), The paradox of the contented female manager: an empirical investigation of gender differences in pay expectation in the hospitality industry,. International Journal of Hospitality Management 19(1): 33-51.

[33] Jarvinen, D. W., and J. G. Nicholls (1996), Adolescents' social goals, beliefs about causes of social success, and satisfaction in peer relations, Developmental Psychology, 32(3): 435-441.

[34] Johnson, D., R. Johnson, and G. Maruyama (1983), Interdependence and interpersonal attraction among heterogeneous and homogeneous individuals: A theoretical formulation and a meta-analysis of the research, Review of Educational Research, 53(1): 5-54.

[35] Maccoby, E. E. (1990), Gender and relationships: A developmental account, American Psychologist, 45(4): 513.

[36] Markus, H., and D. Oyserman (1989). Gender and thought: The role of the self-concept. In M. Crawford and M. Hamilton, Gender and thought (pp.100-127). New York: Springer-Verlag. 
[37] Mitchell, T. R., and W.S. Silver (1990), Individual and group goals when workers are interdependent: Effects on task strategies and performance, Journal of Applied Psychology, 75(2): 185-193.

[38] Morgeson, F. P., and S.E. Humphrey (2006), The Work Design Questionnaire (WDQ): developing and validating a comprehensive measure for assessing job design and the nature of work, Journal of Applied Psychology, 91(6): 1321.

[39] Morrison, R.(2004), Informal relationships in the workplace: Associations with job satisfaction, organisational commitment and turnover intentions, New Zealand Journal of Psychology ,33: 114-128.

[40] Mossholder, K., R. Settoon and S. Henagan (2005), A relational perspective on turnover: Examining structural, attitudinal, and behavioral predictors, Academy of Management Journal 48(4): 607-618.

[41] Niederle, M., and L. Vesterlund (2007), Do women shy away from competition? Do men compete too much? Quarterly Journal of Economics, 122(3): 1067-1101

[42] Nielsen, I., S. Jex and G. Adams (2000), Development and validation of scores on a two-dimensional workplace friendship scale, Educational and Psychological Measurement, 60: 628-643.

[43] Nieva, V., and B. Gutek (1981), Women and work: A psychological perspective, Praeger New York.

[44] Pan, X. and D. Houser (2011), Mating Strategies and Gender Differences in Pro-Sociality: Theory and Evidence, CESifo Economic Studies, GMU Working Paper in Economics No. 12-32.

[45] Price, J. and C. Mueller (1981), A causal model of turnover for nurses, Academy of Management Journal, 24(3): 543-565.

[46] Quigley, N.R., P.E. Tesluk, E.A. Locke, and K.M. Bartol (2007), A multilevel investigation of the motivational mechanisms underlying knowledge sharing and performance, Organization Science,18(1), 71

[47] Rob, R., and P. Zemsky (2002), Social capital, corporate culture, and incentive intensity. RAND Journal of Economics, 33: 243-257.

[48] Rose, A. J., and S. R. Asher (2004), Children's strategies and goals in response to help-giving and helpseeking tasks within a friendship, Child Development, 75(3): 749-763.

[49] Riordan, C. and R. Griffeth (1995), The opportunity for friendship in the workplace: An underexplored construct, Journal of Business and Psychology,10(2): 141-154. 
[50] Shaw, J., M. Duffy, and E. Stark (2000), Interdependence and preference for group work: Main and congruence effects on the satisfaction and performance of group members, Journal of Management, 26(2): 259-279.

[51] Shaw, J. D., N. Gupta, and J.E. Delery (2002), Pay dispersion and workforce performance: Moderating effects of incentives and interdependence, Strategic Management Journal, 23(6): 491-512.

[52] Skaalvik, E. M., and S. Skaalvik (2011), Teacher job satisfaction and motivation to leave the teaching profession: Relations with school context, feeling of belonging, and emotional exhaustion, Teaching and Teacher Education, 27(6): 1029-1038.

[53] Slavin, R. (1977), Classroom reward structure: An analytical and practical review, Review of Educational Research, 47(4): 633-650.

[54] Sy, S. R., D. K. DeMeis, and R. E. Scheinfield (2003), Pre-school children's understanding of the emotional consequences for failures to act prosocially, British Journal of Developmental Psychology, 21(2): 259-272.

[55] Vigil, J. (2007), Asymmetries in the friendship preferences and social styles of men and women, Human Nature, 18(2): 143-161.

[56] Westover, J. H., and J. Taylor (2011), Job satisfaction in the public service: The effects of public service motivation, workplace attributes and work relations, Public Management Review, 13(4): 1-21. 